\title{
Imigração e cidades: uma cartografia da arena pública de apoio aos imigrantes e refugiados em Florianópolis
}

\author{
Immigration and cities: a cartography of the public arena for the immigrants \\ and refugee support in Florianópolis
Inmigración y ciudades: una cartografía de la arena pública para el apoyo a inmigrantes y refugiados en Florianópolis

\author{
Anderson Luís do Espírito Santo ${ }^{1}$ \\ Carolina Andion ${ }^{1}$
}

Recebido em 09/09/2019; revisado e aprovado em 14/01/2020; aceito em 30/01/2020

DOI: http://dx.doi.org/10.20435/inter.v21i4.2717

\begin{abstract}
Resumo: A imigração humana é um processo mundial e histórico e que vem se intensificando nos últimos anos, especialmente com o fenômeno global dos refugiados. Inserindo-se nessa temática mais ampla, este artigo busca discutir como a ação pública diante da imigração vem ocorrendo no âmbito das cidades brasileiras, a partir de um estudo conduzido na cidade de Florianópolis. Tendo por fundamento a sociologia contemporânea dos problemas públicos, de base pragmatista, busca-se compreender como se configura a arena pública que se mobiliza em torno desse problema público no quadro do Ecossistema de Inovação Social da cidade. Como resultado, foi possível, a partir da consideração da historicidade do problema público (escala macro), cartografar as iniciativas de inovação social que atuam junto aos imigrantes/refugiados na cidade (escala meso) e observar as atividades de duas iniciativas que atuam nessa arena pública, buscando levantar seus alcances e limites em termos de influência na ação pública da cidade.
\end{abstract}

Palavras-chave: imigração; Ecossistema de Inovação Social; arenas públicas; ação pública; cidades.

Abstract: Human immigration is a worldwide and historic process that has been intensifying in recent years, especially with the global phenomenon of refugees. As part of this broader theme, this article seeks to discuss how public action in the face of immigration has been taking place in the context of Brazilian cities, based on a study conducted in the city of Florianópolis. Based on the contemporary sociology of public problems, with a pragmatic basis, we seek to understand how the public arena that is mobilized around this public problem is configured within the framework of the city's Social Innovation Ecosystem. As a result, it was possible, based on the historicity of the public problem (macroscale), to map the social innovation initiatives that work with immigrants/refugees in the city (mesoscale) and observe the activities of two initiatives that operate in this public arena, seeking to raise its reach and limits in terms of influence on public action in the city.

Keywords: Immigration; Social Innovation Ecosystem; Public Arenas; Public Action; Cities.

Resumen: La inmigración humana es un proceso mundial e histórico que se ha intensificado en los últimos años, especialmente con el fenómeno global de los refugiados. Como parte de ese tema más amplio, este artículo busca discutir cómo la acción pública frente a la inmigración se ha llevado a cabo en el contexto de las ciudades brasileñas, según un estudio realizado en la ciudad de Florianópolis. Con base en la sociología contemporánea de los problemas públicos, con una base pragmática, buscamos comprender cómo se configura la arena pública que se moviliza en torno a este problema público en el marco del Ecosistema de Innovación Social de la ciudad. Como resultado, fue posible, basado en la historicidad del problema público (escala macro), mapear las iniciativas de innovación social que trabajan con inmigrantes/refugiados en la ciudad (escala meso) y observar las actividades de dos iniciativas que operan en esta arena pública, buscando elevar su alcance y límites en términos de influencia en la acción pública en la ciudad.

Palabras claves: Inmigración; Ecosistema de Innovación Social; Arenas Públicas; Acción Pública; Ciudades.

\footnotetext{
${ }^{1}$ Universidade do Estado de Santa Catarina (Udesc), Florianópolis, Santa Catarina, Brasil.
} 


\section{INTRODUÇÃO}

Desde o fim do século XX, quase todas as nações se tornaram países de imigração. Os imigrantes se deslocam não apenas para as regiões ditas desenvolvidas, mas também para os países em desenvolvimento, como é o caso do Brasil. Atualmente, o fluxo migratório global está se intensificando e diversificando, sendo impulsionado pelo aumento das desigualdades econômicas, sociais e políticas, que levam milhares de pessoas a procurar outro lugar para viver, além das fronteiras nacionais (SAINT-DENIS, 2017).

Nesse universo dos imigrantes - que são todos aqueles que entram em um país diferente da sua nação de origem -, destacam-se os refugiados, definidos pelo Alto Comissariado das Nações Unidas para Refugiados (Acnur), no Estatuto dos Refugiados (1951), como: "as pessoas que se encontram fora do seu país por causa de fundado temor de perseguição por motivos de raça, religião, nacionalidade, opinião política ou participação em grupos sociais e que não possa (ou não queira) voltar para casa" (ACNUR, 2016). Segundo a Agência, após 1951, o conceito se expandiu e hoje também considera, além dos motivos citados, as pessoas que são obrigadas a deixar seu país devido a conflitos armados, gênero, violência e violação massiva dos direitos humanos 2 . O relatório da Organização das Nações Unidas (ONU) - Tendências Globais: deslocamentos forçados 2017 - afirma que existem 258 milhões de migrantes internacionais, dos quais 25,4 milhões deixaram seu país em decorrência de guerras, violência e perseguições, o que os levou a atravessar fronteiras, tornando-se refugiados.

Diante desse quadro, a imigração e a questão do acolhimento aos refugiados se constituem como problemas públicos globais que são vivenciados localmente nas cidades. No Brasil, só em 2018, houve um aumento do fluxo migratório em mais de 160\% (FGV/DAPP, 2018). Em Santa Catarina, esse número triplicou e hoje 5.762 imigrantes e refugiados estão cadastrados em programas sociais, fora os não cadastrados (NSC, 2019). Somente na Grande Florianópolis ${ }^{3}$, a Secretaria de Estado da Assistência Social estima que viva cerca de 8 mil imigrantes haitianos. Além deles, a cidade conta com vários grupos de senegaleses, sírios, angolanos, diversos povos latinos (argentinos, bolivianos, peruanos, uruguaios, colombianos, paraguaios etc.) e tantos outros imigrantes de outras nacionalidades.

O debate acadêmico e também político sobre o enfrentamento dessas questões públicas vem se intensificando nos últimos anos (ARAUJO, 2015; ACNUR, 2016). Nesse debate, as inovações sociais são colocadas como alternativas para ampliar a resiliência das cidades e para o enfrentamento dos atuais problemas urbanos (MCPHEARSON et al., 2014; MEHMOOD, 2016; WOLFRAM; FRANTZESKAKI, 2016). A inovação, neste contexto, já não é considerada apenas como resultado de novas combinações que produzem melhorias em termos econômicos e produtivos, mas também como intervenções que podem promover transformações sociais duradouras (KLEIN; HARRISSON, 2007). Diante disso, torna-se crucial examinar as relações entre as iniciativas de inovação social e as dinâmicas de desenvolvimento dos territórios que, embora específicos e

\footnotetext{
${ }^{2}$ Além desses dois conceitos, o Alto Comisionado de las Naciones Unidas para los Refugiados (ACNUR, 2017) define um migrante internacional como qualquer pessoa que mude de seu país de residência habitual. Quando ele muda por pelo menos um ano, é definido como um migrante de longo prazo; e, quando uma pessoa muda seu local de residência habitual por mais de três meses, mas menos de um ano, é considerado um migrante de curto prazo.

${ }^{3}$ A região metropolitana tem seu núcleo composto pela conurbação de Florianópolis com os municípios vizinhos: São José; Palhoça; Biguaçu; Santo Amaro da Imperatriz; Governador Celso Ramos; Antônio Carlos; Águas Mornas; e São Pedro de Alcântara. Juntos, têm cerca de 1 milhão de pessoas (IBGE, 2017).
} 
locais, estão relacionados aos processos globais (FONTAN et al., 2008) necessários para alcançar uma transformação social mais ampla, transformação necessária para responder a fenômenos globais, como é o caso da imigração e dos refugiados.

Assim, o objetivo deste estudo é analisar como os atores do município de Florianópolis (sejam eles do governo, sejam eles da sociedade civil ou do meio empresarial) estão se mobilizando para tratar a questão dos imigrantes e refugiados na cidade. Busca-se compreender como as práticas de inovação social emergem em torno desse problema público, a partir do mapeamento de organizações que atuam nessa causa e da visita in loco em duas iniciativas. Isso é ilustrado por meio da cartografia do Ecossistema de Inovação Social (EIS) da cidade, ou seja, de um mapeamento realizado a partir da pesquisa do Observatório de Inovação Social de Florianópolis (Obisf), que, entre outros objetivos, busca compreender os efeitos das diversas iniciativas que promovem inovações sociais para o enfrentamento dos problemas públicos nas diferentes arenas públicas da cidade.

Embora o campo de estudos sobre as inovações sociais seja amplo e haja uma infinidade de definições de inovação social (BIGNETTI, 2011; PHILLIPS; GHOBADIAN, 2014; NICHOLS et al., 2015), há um consenso entre os pesquisadores quanto ao fato de definir que esse tipo de inovação refere-se a uma nova resposta para uma necessidade social ou problema público, promovendo mudanças duráveis e em larga escala (LÉVESQUE, 2016). O termo inovação social ganha expressão em 1970 (TAYLOR, 1970), sendo o debate em torno do conceito posteriormente desenvolvido e assumindo hoje destaque tanto no meio acadêmico como no âmbito das políticas públicas (SINCLAIR; BAGLIONE, 2015). Nas últimas duas décadas, a inovação social passou a ser prioridade nas agendas políticas de governos da União Europeia e da América do Norte, com objetivo de promover a melhoria da qualidade de vida, proteção social, combate à pobreza e exclusão social (TEPSIE, 2014). No Brasil, o debate é mais recente e ainda está se consolidando, tendo o termo ganhado expressão, sobretudo, a partir do início de 2010 (BIGNETTI, 2011).

Neste estudo, parte-se de uma compreensão da inovação social como fruto da intervenção de diversos atores, provenientes de múltiplos setores que se mobilizam e agem em torno dos problemas públicos (ANDION et al., 2017a; ANDION; ALPERSTEDT; GRAEFF, 2020). Nesse sentido, torna-se essencial compreender como se constitui a rede que forma os Ecossistemas de Inovação Social (EIS) nas cidades e se esses contribuem ou não para dar respostas a esses problemas públicos. Nos últimos anos, várias mobilizações começaram a eclodir nas cidades em torno do problema da imigração. Assim, começaram a se constituir arenas públicas (CEFAï, 2013; 2017a; 2017b) que problematizam e publicizam as urgências sociais, como é o caso da imigração e dos refugiados.

Para contribuir com esse debate é que realizamos este estudo na cidade de Florianópolis, cujos resultados são apresentados nas próximas sessões. Primeiramente, apresentamos a estratégia de pesquisa e a metodologia utilizada, no quadro da pesquisa mais ampla realizada pelo Obisf. Na sequência, apresentamos o debate em torno dos EIS e sobre o enfrentamento dos problemas públicos das cidades, nas arenas públicas, para finalmente apresentar os resultados da cartografia realizada junto à arena pública de acolhimento aos refugiados de Florianópolis.

\section{ESTRATÉGIA E METODOLOGIA DE PESQUISA}

Este estudo se insere no contexto da atual e crescente problemática mundial da imigração e dos refugiados, analisado sob o prisma da ação pública local, na cidade de Florianópolis. Para isso, foi adotada uma abordagem qualitativa de pesquisa que articulou entrevistas, análise documental, 
aplicação de questionário e levantamento bibliográfico, o que permitiu compreender as ações dos micropúblicos (CEFAÏ, 2013) e como essa ação compõe o EIS da cidade.

Primeiramente, foi realizado levantamento bibliográfico e documental (relatórios e jornais nacionais, internacionais e locais) a partir dos temas-chave desta pesquisa ${ }^{4}$. Na sequência, foi iniciado o mapeamento das iniciativas de inovação social em Florianópolis que atuam na causa do imigrante e refugiado. As primeiras iniciativas foram identificadas na própria revisão documental. Posteriormente, foi possível ir rastreando outras iniciativas, uma após outra, a partir do próprio site delas ou de página no Facebook. Ademais, no momento das entrevistas e da aplicação dos questionários, outras iniciativas foram sendo citadas. A cada citação, buscamos averiguar a sua existência e se está localizada em Florianópolis. Ao confirmar esses dados, foi possível "mapeálas" - momento em que as iniciativas são identificadas e têm informações básicas a serem cadastradas na plataforma do Obisf.

O Observatório de Inovação Social de Florianópolis ${ }^{5}$ (Obisf) é uma plataforma digital e colaborativa que mapeia as redes de inovação social que se mobilizam em torno dos problemas públicos da cidade, incluindo atores de suporte, iniciativas de inovação social e suas interações. Foi criado em 2017 pelos pesquisadores da Universidade do Estado de Santa Catarina (Udesc) e se insere numa pesquisa composta por quatro momentos principais que inter-relacionam três escalas de análise: macro (institucional), meso (ecossistema) e micro (experiências), conforme apresentado na Figura $1^{6}$.

Figura 1 - Framework analítico e metodológico do Obisf

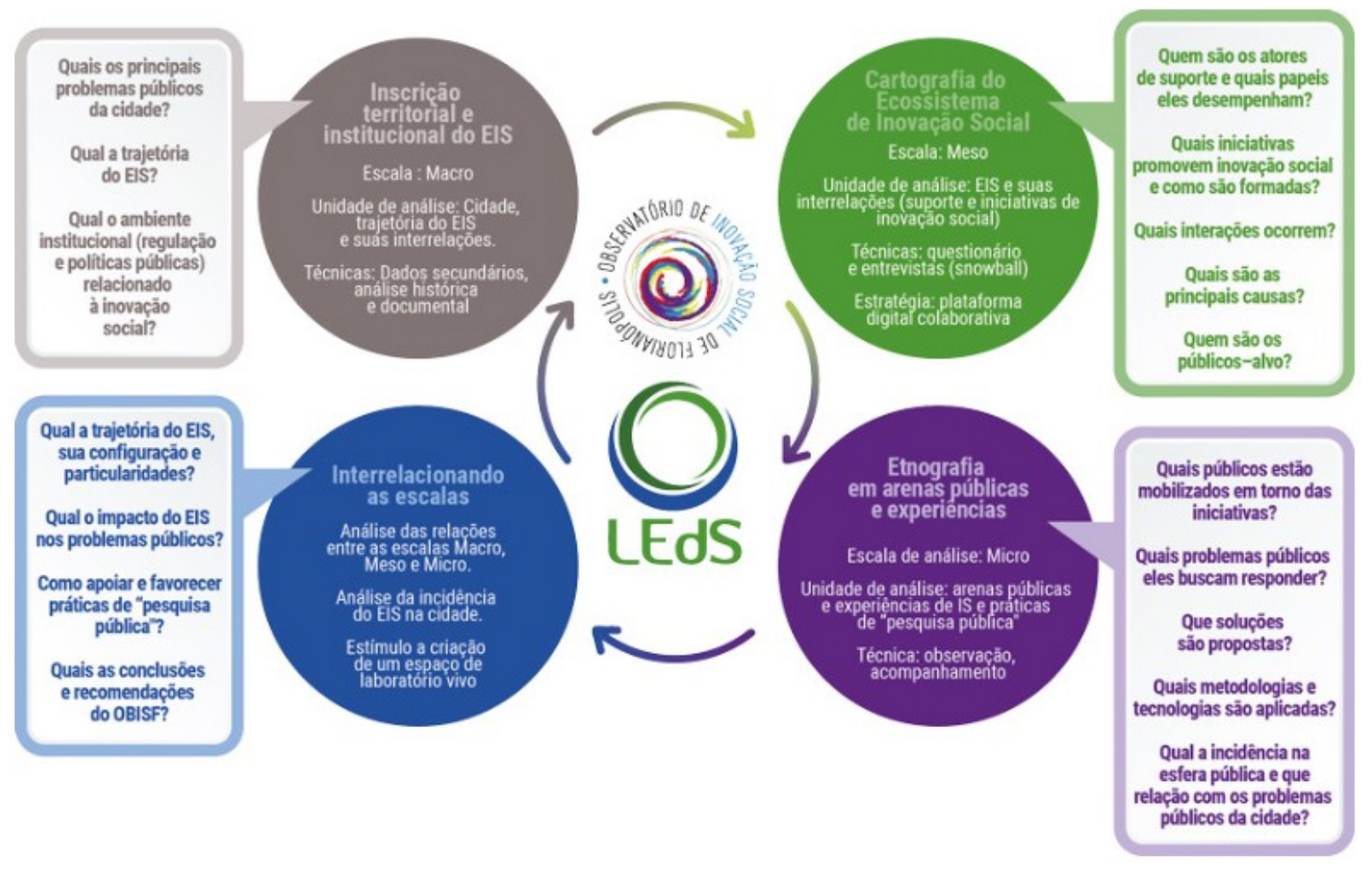

Fonte: Obisf

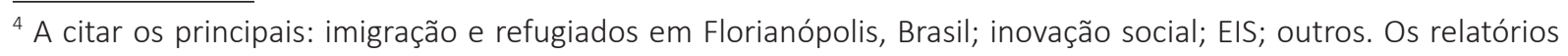
encontrados e utilizados estão citados nas referências deste trabalho.

${ }^{5}$ Observatório de Inovação Social de Florianópolis (http://www.observafloripa.com.br/is-home)

${ }^{6}$ Para um maior detalhamento sobre o Obisf e sobre a pesquisa mais ampla na qual se insere este estudo, ver Andion, Alperstedt e Graeff (2020).
} 
Após o mapeamento e cadastro das iniciativas na plataforma do Obisf, selecionamos como iniciativa principal o Centro de Referência no Atendimento ao Imigrante (Crai), devido à mobilização das diferentes iniciativas mapeadas para a abertura desse Centro, como será narrado nas próximas páginas. Assim, a aplicação do questionário do Obisf foi feita com duas iniciativas7: o Crai e a Ação Social Arquidiocesana de Florianópolis (ASA). Essa opção ocorreu antes do encerramento deste artigo (julho/2019). No entanto, em 20 de setembro de 2019, a assessoria de imprensa do Crai informou que o Centro teve suas atividades encerradas, devido ao fim do contrato entre o Estado de Santa Catarina e a ASA, que coordenava as atividades do Centro. O Estado alegou falta de verba e que o serviço voltou a ser realizado dentro dos Centros de Referência de Assistência Social (Cras).

Ademais, buscando reconhecer como os imigrantes são percebidos pela população local, também foram realizadas entrevistas em dois momentos. Primeiro, com 25 pessoas no início desta pesquisa, em novembro de 2017, em três bairros da cidade. O segundo momento ocorreu em janeiro de 2019, com mais 40 pessoas, em outros três bairros de Florianópolis. Nos dois momentos, 100\% dos entrevistados afirmaram residir em Florianópolis e disseram perceber, ou já terem percebido, a presença do imigrante na cidade, o que validou a sua participação na pesquisa. Foi considerada a técnica do snowball para encerrar as entrevistas - momento em que as respostas começaram a se repetir, indicando a saturação.

Também foram entrevistados 30 imigrantes e refugiados na cidade, pois importava saber se eles conheciam as atividades de algumas das iniciativas da sociedade civil que atuam nessa causa. Buscamos os locais onde eles mais se concentram: o centro da cidade e próximo a duas praias. Esses locais são muito procurados por eles para realizar vendas de diferentes artigos, como roupas, acessórios, pequenos produtos eletrônicos, lanches, entre outros. Todos os participantes já conheciam, no mínimo, uma das iniciativas mapeadas.

A leitura de todo esse material foi feita sob a ótica da sociologia contemporânea dos problemas públicos, de base pragmatista (ANDION et al., 2017a), que analisa a ação pública e a capacidade crítica dos atores a partir de suas práticas, inter-relacionando as dimensões micro (ações individuais e das interações) e macro (totalidades sociais) para (re)considerar a experiência dos atores, por meio do resgate da historicidade que configura a vida desses e os enunciados, a fim de entender como a ação se inscreve. Assim, foi possível: i) identificar uma breve historicidade do problema público (análise macro); ii) cartografar as iniciativas de inovação social que atuam junto aos imigrantes/refugiados na cidade (escala meso); iii) analisar duas iniciativas de inovação social (análise micro); iv) perceber o posicionamento dos moradores locais e dos imigrantes e refugiados que estão vivendo na cidade.

\section{ENFOQUE TEÓRICO E ANALÍTICO: DOS ECOSSISTEMAS DE INOVAÇÃO ÀS ARENAS PÚBLICAS}

Nos últimos anos, vem se intensificando o debate acadêmico e também político, em diferentes países, em torno da temática da inovação social (HOWALDT; SCHWARZ, 2010; KLEIN et al., 2016). No entanto estudos sobre a emergência e os efeitos dos Ecossistemas de Inovação Social (EIS) e sua real incidência nas dinâmicas de desenvolvimento dos territórios são ainda

7 Primeiramente, as iniciativas são "mapeadas" no Obisf. Quando ocorre a aplicação do questionário (visita in loco), elas mudam para "observadas", o que aconteceu com essas duas. Na Figura 4, é possível ver essa diferença. 
muito recentes e escassos (LÉVESQUE, 2016; ANDION; ALPERSTEDT; GRAEFF, 2017b). Aqui a inovação social é interpretada como um processo político no sentido de uma transformação social. Conforme Howaldt e Schwarz (2010), a inovação social é uma intervenção que produz mudança, fruto da mobilização de diferentes atores, da coprodução de conhecimentos e execução de novas ideias que podem responder aos desafios públicos.

Para Lévesque (2016) e Andion, Alperstedt e Graeff, (2017b), os modelos explicativos oriundos das abordagens empresariais (empreendedoras) surgem para ilustrar como ocorre a formação dos Ecossistemas Empreendedores (EE) e têm uma operacionalização e real aplicabilidade muito baixa, quando destinados à análise e compreensão dos EIS, pois o EE, apesar de possuir metodologias e requisitos muito bem definidos que permitem identificar o ecossistema de sucesso, não considera algumas particularidades, como a trajetória (razões de seu surgimento), a composição, o contexto institucional e as consequências (reais e práticas) das inovações sociais (IS) sobre os territórios. Os modelos do EE priorizam mais as ofertas dos ecossistemas (as instituições de suporte) em detrimento da sua relação com as demandas, sejam elas as iniciativas de IS, sejam elas os problemas públicos em torno dos quais os atores dos EIS se mobilizam.

Em decorrência disso, estudos mais recentes alertam para a necessidade de construir "frameworks menos normativos ou prescritivos para compreender as inovações sociais e seus efeitos, focando em outras dimensões dos EIS e em suas relações, apresentando uma abordagem mais ampla e complexa de análise" (ANDION; ALPERSTEDT; GRAEFF, 2017b, p. 1).

O desenvolvimento de estudos e pesquisas mais profundos sobre EIS ainda é limitado e carece de mais teorização. Kaletka et al. (2016) apresentam que o approach dos EIS permitirá compreender a importância da noção de "ambiente" para as IS mais relevantes, intensamente ligadas à diversidade de entendimentos de inovação social. Isso porque o ambiente impactará sobre a forma como determinado problema público será tratado-compreendido. "Neste contexto, a ideia de um EIS ajuda a superar concentração no empresário social como agente-chave da mudança" (KALETKA et al., 2016, p. 85). Trata-se de reforçar uma antropologia da política cotidiana, buscando "elucidar como atores comuns transformam a realidade social" (ANDION; ALPERSTEDT; GRAEFF, 2017b, p. 4).

Captar as dinâmicas de inovação social nessa perspectiva implica considerar o processo de mudança social. Isso sugere rastrear um determinado problema público e colocar a ênfase nos públicos que se mobilizam em torno dele. Por sua vez, um problema se torna público quando ele cristaliza o sentimento de uma coletividade. Surge a partir da insatisfação de uma dada controvérsia (GUSFIELD, 1981). Nesse sentido, é importante compreender como as inovações sociais são promovidas no território, ancorando os movimentos de mudança urbana mais firmemente no tecido social e político local (MOULAERT et al., 2007). Por isso a necessidade de rastrear as mobilizações em torno do problema público nas diversas "arenas públicas" (CEFAÏ, 2017a; 2017b) e buscar compreender quais são as situações de provas, as conquistas, as lutas, mas também os lugares de silêncio e os retrocessos.

Arenas públicas são compreendidas neste estudo como "laboratórios de ação pública”, nos quais é possível reconhecer as mobilizações, as controvérsias, conflitos e acordos entre os atores que estão em diferentes posições de poder, a respeito de um determinado problema público. Em suma, essa percepção de inovação social pode ajudar a compreender como os diferentes públicos se mobilizam para buscar novas respostas de efeito duradouro que promovam o desenvolvimento, o interesse público e a garantia da democracia (DEWEY, 1927). 


\section{COMO FLORIANÓPOLIS PERCEBE A QUESTÃO DO IMIGRANTE? DO INCÔMODO À SITUAÇÃO PROBLEMÁTICA}

O centro de Florianópolis transformou-se em uma verdadeira "praça de guerra" após a (suposta) prisão arbitrária de mais um imigrante que atuava como ambulante no centro da cidade. Essa frase, que consta em reportagem veiculada em um jornal local de Florianópolis (JORNALISTAS LIVRES, 2019), está longe de ser uma notícia corriqueira de um evento isolado. Ela revela e expressa uma tensão social que suscita um debate para uma "urgência social" (CEFAï, 2013) em torno da causa dos imigrantes e refugiados, uma questão que afeta não apenas Florianópolis, mas várias cidades do mundo na atualidade.

Um exemplo disso é a história apresentada pelo Jornal Notícias do Dia, em que o jovem Bredeley, haitiano de 30 anos, conseguiu em maio de 2015 a sua carteira de trabalho na cidade de Florianópolis, na Superintendência Regional de Trabalho e Emprego (SRTE-SC). Além dele, outros tantos haitianos, senegaleses e sírios esperavam pela mesma oportunidade conquistada por Bredeley, que relatou: "Quero encontrar logo um emprego, trabalhar e poder ajudar meus irmãos e meu filho que ficaram no Haiti" (THOMÉ, 2015, p. 1).

Como se sabe, desde 2004, o mundo assiste à explosão de violência que assolou a população do Haiti (especialmente na capital Porto Príncipe, principal palco dos conflitos), decorrente de uma histórica ditadura militar e uma intensa miséria que continua a flagelar o povo haitiano. Desde então, comandados pela Organização das Nações Unidas (ONU), diversos países e Organizações da Sociedade Civil (OSCs) internacionais se empenharam em ajudar a população caribenha a dizimar a guerra e a reconstruir o país. O Brasil ajudou com missão militar, envio de alimentos, medicação e, entre outros auxílios, recebeu (legalmente) inúmeros imigrantes no território nacional. Contudo a população haitiana ainda sofreu, em 2010, uma grande catástrofe ambiental (terremoto), que provocou a morte de 230 mil pessoas, deixando 300 mil feridos. Todos esses eventos intensificaram o processo de emigração do povo haitiano para diversas partes do mundo (legal ou ilegalmente) e a ampliação do número de refugiados originários desse país. Um dos destinos mais procurados é o Brasil (BBC BRASIL, 2010; THOMÉ; DIOGO, 2014; THOMÉ, 2015; ARAÚJO, 2015; FERREIRA, 2017).

O caso emblemático descrito contextualiza uma pessoa (Bredeley) advinda de um determinado país (Haiti). Outras histórias semelhantes a essa poderiam ser relatadas das mais diversas formas e motivos e oriundas de diferentes países do globo. Fato é que o Brasil é um país muito procurado pelos imigrantes que buscam melhores condições de vida. "Os mesmos processos econômicos que criam migrantes em regiões periféricas simultaneamente os atraem para países mais desenvolvidos" (MASSEY et al., 1998, p. 38).

Do ponto de vista legal, a Constituição Federal brasileira, no seu princípio da igualdade, apresenta: "Todos são iguais perante a lei, sem distinção de qualquer natureza, garantindose aos brasileiros e aos estrangeiros, residentes no País, a inviolabilidade do direito à vida, à liberdade, à igualdade, à segurança e à propriedade" (BRASIL, 1988, p. 17). Nessa afirmativa, a própria Constituição Federal baliza a proteção e dá direitos aos estrangeiros residentes no país. No entanto, como dar proteção, se é de conhecimento público que milhares de estrangeiros entram ilegalmente pela extensa fronteira brasileira? A fronteira controlada, vista pelo Estado e alimentada pelo controle de quem entra e sai (presença militar/segurança), não funciona no Brasil. Em seus $15.735 \mathrm{~km}$ terrestres de fronteira seca, essa é a principal porta de entrada dos imigrantes (SANTO, 2018). 
Buscar compreender o processo imigratório no Brasil demanda uma ampla análise para que um problema se torne descritivel (BARTHE et al., 2016), sendo preciso considerar as questões mais amplas (macro) até análises micro. Por isso, é preciso resgatar que a imigração em todo o Brasil ${ }^{8}$ ocorre desde a vinda dos portugueses e espanhóis, passando pela escravidão, grupos europeus e asiáticos, desenvolvimento industrial e todo o desenrolar dos séculos XX e XXI. Ao analisar o fluxo imigratório em Florianópolis, percebe-se que todos os que transitam pela cidade são imigrantes permanentemente de passagem firmados na ilusão de uma presença necessariamente provisória, pois, segundo Oliveira (2009, p. 85), “o imigrante é um ser fora do lugar, um ente que busca, incansavelmente, refletir-se naquilo que ainda não existe para ele: o novo lugar iludido, e a sombra dessa ilusão, o imigrante se rende e vive".

Thomé (2015) apresenta que o estado de Santa Catarina emitiu, somente no ano de 2015, mais de duas mil carteiras de trabalho para trabalhadores haitianos. Ainda segundo o autor, fundamentado nos dados da Polícia Federal, o número de haitianos registrados no estado, até maio de 2015, era de 3.500 pessoas. Contudo nem só de conquistas vivem os imigrantes em Florianópolis. De acordo com o jornal A Hora de Santa Catarina, em abril de 2017, um grupo de senegaleses (Figura 2), que não tinham licença para trabalhar como ambulantes, protestaram em frente à Catedral Metropolitana pedindo a legalização do trabalho como ambulante e o fim da violência na fiscalização. O grupo afirma que sofre preconceito e que a repressão da Guarda Municipal e da Polícia Militar é intensa.

Relatos de ataques, xenofobia e preconceito são narrados com frequência pela mídia local. O caso mais recente aconteceu em abril de 2019, quando 10 homens da Guarda Civil apreenderam a mercadoria de um trabalhador senegalês que vendia camisetas e bermudas no centro da cidade. $\mathrm{Na}$ oportunidade, o vídeo da matéria apresenta trocas de ofensas raciais e outras verbais, o que demonstra o quanto a urgência social da causa dos imigrantes e refugiados é imprescindível na cidade. $\mathrm{O}$ assunto teve tanta reverberação que diversos imigrantes e refugiados foram protestar na delegacia de polícia de Florianópolis (Figura 3).

Figura 2 - Imigrantes protestando em Florianópolis

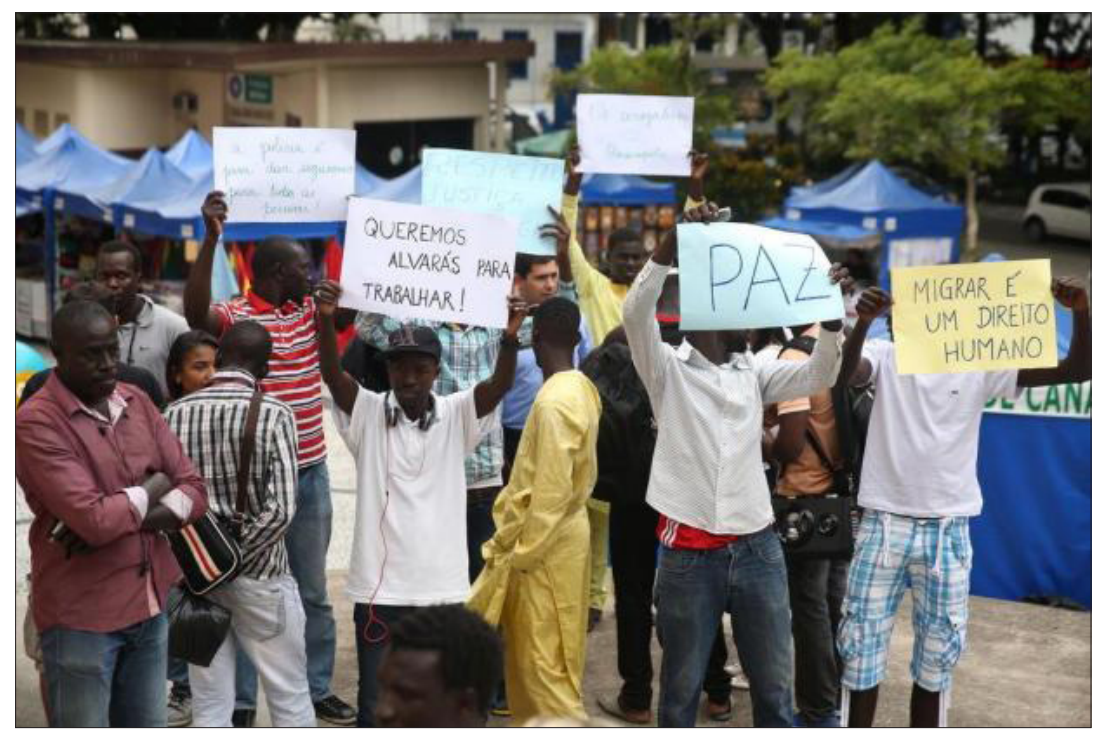

Fonte: Jornal A Hora de Santa Catarina, 2017.

\footnotetext{
${ }^{8}$ Para uma maior análise nesse campo, ver Vetrano (2015).
} 
Figura 3 - Imigrantes protestando

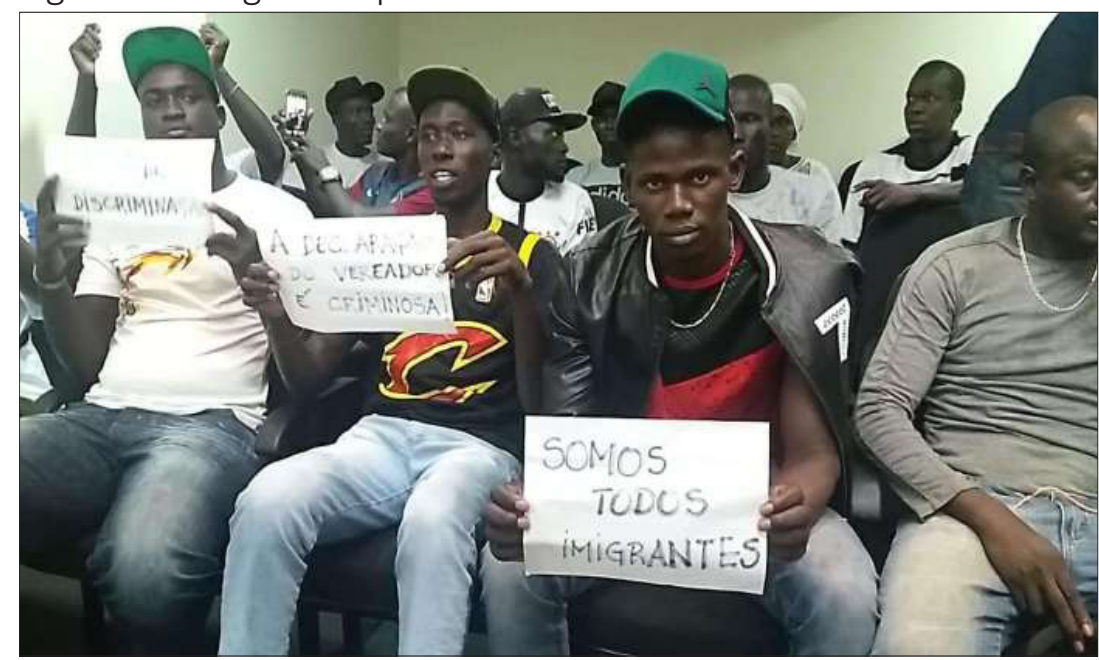

Fonte: Jornalista Livre, 2019.

A partir dos argumentos narrados, temos diversos "momentos críticos" (BOLTANSKY; THÉVENOT, 1999) que demonstram o tempo, as atividades críticas e os momentos de crise. Um momento crítico surge por meio do incômodo, quando as pessoas se dão conta de que há algo errado, que não conseguem mais conviver com um dado problema, ou que algo mudou. Esses momentos surgem de tempos em tempos e emergem quando os atores acabam por tentar depurar ações e práticas que possam impactar o seu vínculo social.

Nos casos apresentados, é possível verificar alguns momentos críticos nas seguintes passagens: para a população haitiana, devido à guerra civil pela qual o país passou e acabou intensificando a vinda desses imigrantes para o Brasil; para os agentes do governo em Florianópolis, em que, entre outras ações, a Polícia Federal passou a estreitar os laços para controlar o número de imigrantes e a Superintendência Regional do Trabalho e Emprego (SRTESC) começou a controlar a liberação das carteiras de trabalho para os imigrantes; e os próprios imigrantes na cidade, que começaram a se manifestar acerca do seu reconhecimento e do fim do preconceito recebido do poder público.

Partindo de tais constatações vem a pergunta: Será que os habitantes da cidade percebem a imigração como problema público? Em outras palavras, a imigração se constitui em uma situação problemática para o cidadão comum de Florianópolis?

Buscando reconhecer como os imigrantes são percebidos pela população local, foram realizadas 65 entrevistas com moradores que disseram perceber, ou já terem percebido, a presença do imigrante na cidade. Contudo, algumas falas chamam atenção.

Eu me preocupo com a presença do imigrante. Emprego já está tão difícil aqui em Floripa e agora temos que disputar vagas com eles. O Brasil foi precipitado quando resolveu aceitar tantos imigrantes. A ilha tá lotada! (E. 1).

Eu moro aqui na Lagoa [bairro] e, alguns dias atrás, participei da feira do imigrante. Foi um evento muito bonito e importante para quebrar o preconceito das pessoas. (E. 2).

Não vejo como problema. Eu penso que meus avós [origem italiana] vieram para cá e hoje a família está grande e vive bem. Será que se ficássemos lá [na Itália] tudo seria igual? (E. 3). No início até é interessante, mas daí eles [os imigrantes] não conseguem emprego, nem falar o português direito [...] ficam tudo ilegal! Daí é a hora que começam a vender drogas 
e até a se prostituir. (E. 4).

Eu vejo que eles sofrem muito preconceito e que algo precisa ser feito. (E. 5).

Observamos nas falas acima algumas opiniões, expressões e visões diferenciadas sobre os imigrantes. As falas nos remetem a Sayad (2004), quando o autor expõe que o imigrante é muito mais do que um indivíduo que deixa a sua terra em busca de um novo lugar para viver (falas de $\mathrm{E}$. 2 e E. 3). Trata-se de um indivíduo complexo, que tem um motivo para deixar seu local de origem. Sayad (2004) aponta que o imigrante muitas vezes é visto como um parasita (na fala de E. 1) que invade o novo sistema e serve como força de trabalho, passando a constituir um problema para o país que o utiliza (fala de E. 4). No entanto ele deve ser interpretado para além dessa visão (fala de E. 2; E. 3 e E. 5), já que, por exemplo, em Florianópolis, é impossível interpretar a cidade sem a presença dos imigrantes - seu papel social, cultural, econômico e na força de trabalho (fala de E. 2). A emergência desses novos sujeitos chama os pesquisadores a olharem com mais ênfase as arenas, buscando compreender como ocorre a integração desse novo sujeito na sociedade.

O imigrante só existe na sociedade que assim o denomina a partir do momento em que atravessa suas fronteiras e pisa em seu território; o imigrante "nasce" nesse dia para a sociedade que assim o designa. Assim, ela se arvora o direito de desconhecer tudo o que antecede esse momento e esse nascimento. (SAYAD, 2004, p. 16).

Diante do exposto, é possível afirmar que a pauta dos imigrantes vem pouco a pouco se transformando numa "questão", numa "situação problemática" (CEFAI 2017a; 2017b) para a população de Florianópolis. Essa situação problemática é confrontada a partir de diversas posturas e argumentos, desde posições discriminatórias (sobretudo xenofobia e racismo), mais comuns, que enxergam os imigrantes como "ameaças", as quais podem levar a agressões físicas, verbais e emocionais; até a postura de busca de alternativas de inclusão social para essas pessoas, enxergandoas como capazes de contribuir por meio do trabalho com o desenvolvimento da cidade.

Diante desses incômodos e das controvérsias geradas a partir deles, a ação pública de diferentes grupos começou a inserir a questão na agenda de desenvolvimento na cidade, o que culminou com distintas mobilizações coletivas. Ainda longe de se constituir como uma ação organizada, com controle imigratório e inserção desses imigrantes na sociedade civil local, Florianópolis contou, até setembro de 2019, com a atuação do Crai, que, além do atendimento, congregava diversas iniciativas da sociedade civil. Esse fechamento causou a preocupação nos imigrantes e demais atores que apoiam a causa (JORNAL NDMAIS, 2019), devido aos riscos que essa ação representa, sendo o principal a falta de um atendimento especializado e o apoio e acolhimento de forma mais rápida.

\section{QUAL ARENA PÚBLICA? DA EXCLUSÃO À URGÊNCIA SOCIAL}

O Crai foi uma entidade com objetivo de atuar com a acolhida e o apoio aos imigrantes na região da Grande Florianópolis. Durante a realização deste estudo, ele estava sendo coordenado pela Pastoral do Migrante (ASA), sob liderança do Padre Sérgio Jeremia, que nos concedeu uma entrevista. Isso permitiu acompanharmos as experiências de duas iniciativas (Crai e ASA observadas) que atuam junto de uma rede de colaboradores que foram mapeados e inseridos na plataforma do Obisf, o que possibilitou identificar a cartografia da arena pública que atua na causa dos imigrantes e refugiados (Figura 4). 
A Figura 4 apresenta a rede de EIS encontrado até o momento nesta pesquisa e que vem atuando em torno da causa do imigrante/refugiado na cidade de Florianópolis. A ação pública empreendida por esses diferentes coletivos busca de alguma forma contribuir com o problema público instaurado. São as práticas desses atores que vêm promovendo dinâmicas de desenvolvimento mais sustentáveis na cidade (ANDION; ALPERSTEDT; GRAEFF, 2020), como é o caso do Crai e da ASA.

Figura 4 - EIS dos imigrantes e refugiados em Florianópolis

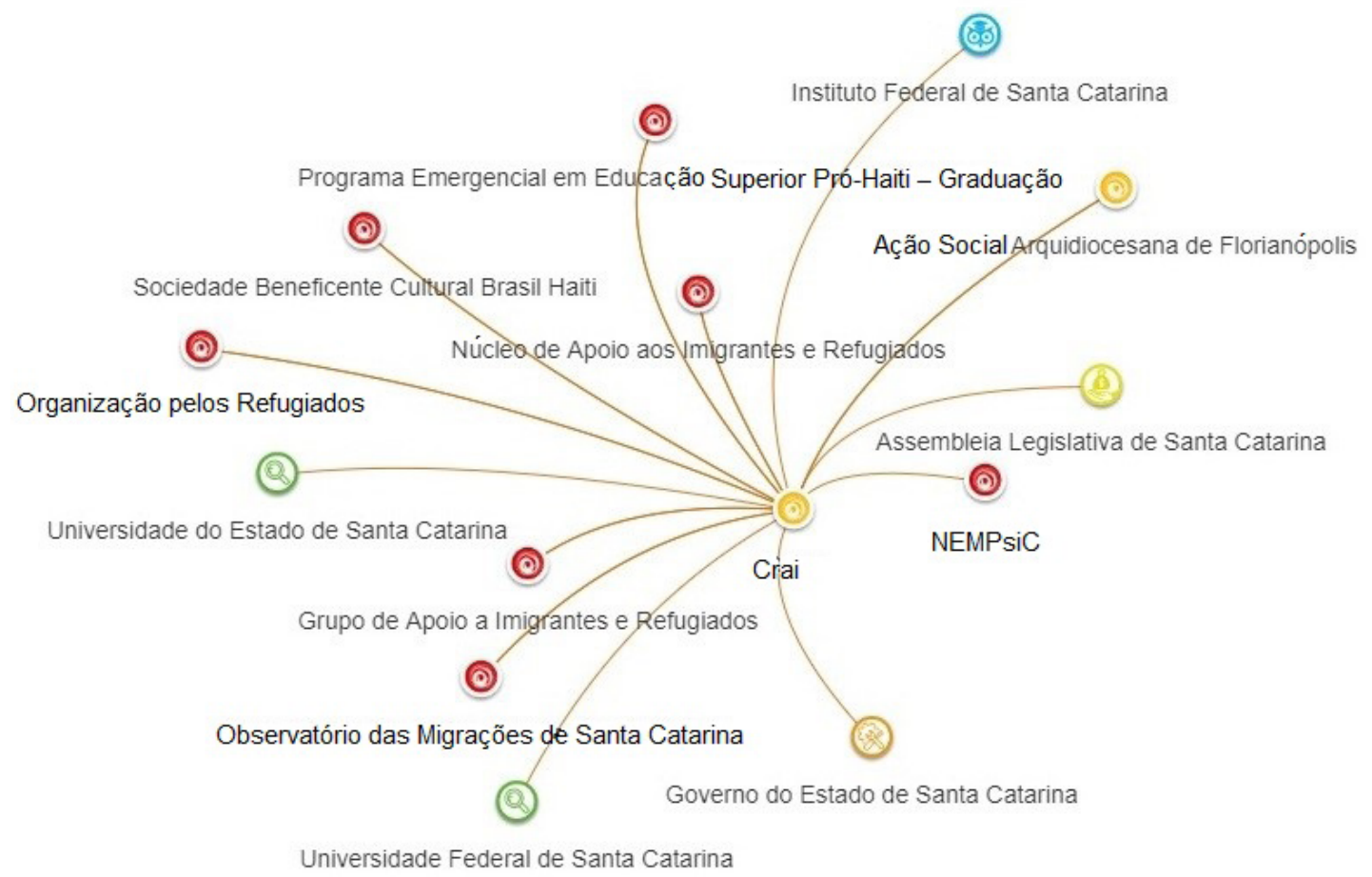

(Q) Instituição de Ensino e Pesquisa

(C) Observadas: Iniciativas que tiveram suas informações validadas pela equipe do Obisf

(2) Mapeadas: Iniciativas de IS cadastradas na plataforma

Fonte: Dados da Pesquisa.

O Crai foi constituído com a missão de dar suporte aos imigrantes e refugiados. Atuava, especialmente, com atendimento individual e familiar e prestava auxílio com relação a benefícios sociais, documentação e apoio psicológico. No início, uma das principais barreiras encontradas para a implantação do Crai foi a resistência por parte do governo municipal, que não via com bons olhos a abertura de um centro de assistência aos imigrantes dentro da ilha, conforme relatou Pe. Sérgio.

Os primeiros Crais surgiram no Brasil em São Paulo (2014) e em Porto Alegre (2014). Tal surgimento incentivou ainda mais as mobilizações em Florianópolis, iniciadas em 2014 por meio de seminários organizados pelo Grupo de Apoio aos Imigrantes e Refugiados de Florianópolis (Gairf) e pelo Fórum das Associações aos Migrantes. A falta de diálogo com o governo estadual e municipal fez eclodir, em outubro de 2015, uma mobilização dos imigrantes e refugiados, que exigiam do governo estadual a criação de um espaço que Ihes dessem apoio e acolhida. Somente um ano depois, em setembro de 2016, foi assinado um contrato entre o Governo Federal, Estadual e a ASA, que previa a abertura do Crai em Florianópolis, com um aporte inicial de R\$ 700 mil (do total de R\$ 1 milhão) 
para os dois primeiros anos do centro. Na oportunidade, tal vitória foi celebrada com um abraço coletivo no Terminal Rodoviário de Florianópolis, onde ficaria a sede do Crai.

Catorze meses depois, novas mobilizações surgiram na cidade, em novembro de 2017. Dessa vez, a audiência pública "Migrar é direito! Desafios atuais na construção de políticas públicas com imigrantes e refugiados em Santa Catarina" tratou sobre o descaso com o Crai, que, apesar da autorização, celebração do contrato e recurso destinado, ainda não estava em operação. Ainda não havia sede e o valor inicial foi bloqueado pelo governo estadual. Ao final dessa audiência, ficou acertado que seria elaborada uma carta aberta de apoio ao Crai, redigida coletivamente pelo Grupo de Trabalho do Imigrante (GTI) da Comissão de Direitos Humanos da Assembleia Legislativa do Estado de Santa Catarina (Alesc) e demais OSCs presentes, anexando um abaixo-assinado feito com o apoio de todos que compareceram à audiência pública, em que foi solicitada uma audiência de conciliação para tentar resolver os impasses e efetivar a implementação do centro.

O Crai só foi inaugurado em 5 de fevereiro de 2018, tendo como sede um prédio no centro de Florianópolis. Trata-se de um dispositivo municipal de atenção especializada a um problema público e que legitima a Lei da Migração (Lei n. 13.445/2017), ao dar apoio aos imigrantes e refugiados.

Passados 10 meses da sua abertura, o Crai enfrentou suas primeiras incertezas sobre o seu funcionamento devido aos atrasos no repasse financeiro. Segundo o jornal Migra Mundo (2018), a ASA foi surpreendida com uma possível finalização do contrato, já que o termo firmado inicialmente em 2014 só foi iniciado em 2018. Na ocasião, o Crai teve seus serviços suspensos por dois dias. Resolvido esse trâmite jurídico, voltou às suas atividades e, pretendendo fortalecer a pauta, promoveu a audiência "Políticas Públicas para Imigração em SC", em novembro de 2018, que teve a participação do poder público e de diversas OSCs. Até aquele momento, o Crai chegou a atender 800 imigrantes e refugiados ao mês e, até o fim de 2018, realizou mais de 7 mil atendimentos. No entanto esses números não serviram para institucionalizar ainda mais a pauta, e o Crai foi encerrado após a finalização do contrato celebrado entre o Governo Federal, Estadual e a ASA, sob a justificativa de falta de recursos.

Ao longo da trajetória do Crai, inúmeras OSCs foram surgindo por diferentes coletivos da sociedade civil, a fim de tratar diversas questões em torno dessa problemática, como o emprego, a acolhida, dificuldades com a língua, saúde, preconceito etc. O Quadro 1 apresenta as OSCS identificadas por esta pesquisa.

Quadro 1 - Iniciativas de IS que atuam na causa dos imigrantes e refugiados em Florianópolis

\begin{tabular}{|c|c|}
\hline $\begin{array}{c}\text { Iniciativas de inovação } \\
\text { social que compõem a } \\
\text { arena pública }\end{array}$ & OBJETIVo \\
\hline $\begin{array}{c}\text { Ação Social } \\
\text { Arquidiocesana de } \\
\text { Florianópolis (ASA) }\end{array}$ & $\begin{array}{l}\text { É uma associação que, na causa dos imigrantes e refugiados, busca dar } \\
\text { respostas adequadas ao atendimento das demandas trazidas por essas } \\
\text { pessoas e proporcionar novas oportunidades de vida. }\end{array}$ \\
\hline $\begin{array}{c}\text { Grupo de Apoio aos } \\
\text { Imigrantes e Refugiados } \\
\text { de Florianópolis (Gairf) }\end{array}$ & $\begin{array}{l}\text { O grupo busca integrar os imigrantes à sociedade brasileira por meio da } \\
\text { criação de uma convivência com as pessoas da comunidade e do local de } \\
\text { trabalho em que estão inseridos. }\end{array}$ \\
\hline $\begin{array}{c}\text { Núcleo de Apoio aos } \\
\text { Imigrantes e Refugiados } \\
\text { (Nair) }\end{array}$ & $\begin{array}{l}\text { É uma atividade promovida pelo Eirenè (curso de Relações Internacionais } \\
\text { da UFSC), que busca promover ações concretas destinadas à integração } \\
\text { dos imigrantes e refugiados em Florianópolis. }\end{array}$ \\
\hline
\end{tabular}




\begin{tabular}{|c|c|}
\hline $\begin{array}{l}\text { Iniciativas de inovação } \\
\text { social que compóem a } \\
\text { arena pública }\end{array}$ & OBJETIVO \\
\hline $\begin{array}{l}\text { Organização pelos } \\
\text { Refugiados (ORP) }\end{array}$ & $\begin{array}{l}\text { Auxiliam os refugiados que chegam à cidade em busca de melhores } \\
\text { condições de vida e lutam contra o preconceito dentro da sociedade. }\end{array}$ \\
\hline $\begin{array}{l}\text { Centro de Referência } \\
\text { (Crai) }\end{array}$ & $\begin{array}{l}\text { A entidade tem por objetivo atuar com a acolhida e o apoio aos imigrantes } \\
\text { na região da Grande Florianópolis. }\end{array}$ \\
\hline $\begin{array}{l}\text { Feira Gastronômica do } \\
\text { Imigrante }\end{array}$ & $\begin{array}{l}\text { O evento é promovido pela Associação Cultural Cachola de Bernunça; } \\
\text { Coletivo Imigra Brasil; Gairf; Nair; e ASA. Tem por objetivo disseminar a } \\
\text { culinária e a cultura de diversos países dos imigrantes. }\end{array}$ \\
\hline $\begin{array}{l}\text { Feira de Arte e } \\
\text { Culinária do Imigrante } \\
\text { de Florianópolis }\end{array}$ & $\begin{array}{l}\text { A iniciativa é fruto de um termo de cooperação firmado entre a Pre- } \\
\text { feitura, Igeof e Crai para promoção da inclusão social de imigrantes por } \\
\text { meio de economia solidária. }\end{array}$ \\
\hline $\begin{array}{l}\text { Instituto Federal de Santa } \\
\text { Catarina (IFSC). (Campus } \\
\text { de Floripa) }\end{array}$ & $\begin{array}{l}\text { Em parceria com o Gairf, atua em duas frentes: capacitação de mão de } \\
\text { obra imigrante (curso de manipulação de alimentos) e curso de Língua } \\
\text { Portuguesa para Imigrantes. }\end{array}$ \\
\hline $\begin{array}{l}\text { Associação de Estudantes } \\
\text { Haitianos da UFSC (AEH). }\end{array}$ & $\begin{array}{l}\text { A associação tem } 30 \text { acadêmicos que vieram do Haiti para estudar na } \\
\text { UFSC, por meio do Programa Emergencial em Educação Superior Pró- } \\
\text { Haiti. É um espaço de referência e promove eventos culturais. }\end{array}$ \\
\hline $\begin{array}{l}\text { Associação de Haitianos } \\
\text { em Santa Catarina } \\
\text { (AHSC). }\end{array}$ & $\begin{array}{l}\text { Objetiva dar suporte e apoio aos imigrantes haitianos que chegam a } \\
\text { Santa Catarina. Foi identificado que existem outras associações haitianas } \\
\text { pelo estado: em Chapecó e em Balneário Camboriú. }\end{array}$ \\
\hline $\begin{array}{l}\text { Programa Emergencial } \\
\text { em Educação Superior } \\
\text { Pró-Haiti - Graduação }\end{array}$ & $\begin{array}{l}\text { O programa foi idealizado pela Secretaria de Educação Superior (SESu) } \\
\text { do Ministério da Educação e pelo Ministério das Relações Exteriores, } \\
\text { sendo implantado pela UFSC, que atende graduandos haitianos. }\end{array}$ \\
\hline $\begin{array}{l}\text { Sociedade Beneficente } \\
\text { Cultural Brasil Haiti }\end{array}$ & $\begin{array}{l}\text { A sociedade busca, de todas as maneiras possíveis, entregar acolhimento } \\
\text { e assistência aos imigrantes haitianos. }\end{array}$ \\
\hline $\begin{array}{l}\text { Observatório das } \\
\text { Migrações de SC }\end{array}$ & $\begin{array}{l}\text { É grupo interdisciplinar (Faed-Udesc) que trabalha em migração, gênero, } \\
\text { raça, etnia, refugiado e asilo. }\end{array}$ \\
\hline $\begin{array}{l}\text { Grupo de Trabalho de } \\
\text { Apoio a Imigrantes e } \\
\text { Refugiados (GTI) }\end{array}$ & $\begin{array}{l}\text { É um grupo focal de discussões em SC, formado por entidades } \\
\text { da sociedade civil, universidades e os órgãos públicos que atuam } \\
\text { diretamente com o público imigrante ou refugiado. }\end{array}$ \\
\hline $\begin{array}{l}\text { NEMPsic-Clínica } \\
\text { Intercultural }\end{array}$ & $\begin{array}{l}\text { O NEMPsiC (departamento de Psicologia - UFSC) interessa-se pela } \\
\text { temática dos processos migratórios no que diz respeito ao âmbito } \\
\text { psíquico e foca suas práticas no contexto da psicologia clínica intercultural } \\
\text { e da saúde mental. }\end{array}$ \\
\hline
\end{tabular}

Fonte: Os autores.

A importância de todas essas iniciativas ficou clara no momento das entrevistas junto aos imigrantes, quando foi perguntado se eles tinham conhecimento dessas iniciativas e se faziam uso dos serviços prestados. Cem por cento dos respondentes disseram que sim, que antes mesmo de saírem dos seus países já sabiam como chegar até Floripa e da existência de algumas dessas iniciativas. Essa afirmativa também foi relatada pelo Pe. Sérgio, que exemplificou o caso dos haitianos, bolivianos e paraguaios que chegam à cidade. As organizações mais citadas foram a ASA, o Gairf e o Nair, e os serviços mais procurados foram apoio com documentação, língua portuguesa, orientação jurídica e cesta básica. Ainda, o Crai foi apontado como uma vitória para 
os imigrantes e refugiados e para os moradores locais. "Foi uma luta do nosso povo e de todos que nos acolheram", relatou o entrevistado sírio. Para o Jornal NDMAIS, os imigrantes expressaram preocupação com o encerramento das atividades do Crai. Preocupação essa compartilhada com os especialistas do Crai, visto que os Cras, que já têm um alto atendimento nos bairros de Florianópolis, passariam a ter em torno de mil atendimentos a mais por mês, número que o Crai vinha recebendo mensalmente (NDMAIS, 2019).

Já a ASA é uma associação civil sem fins econômicos, parceira do Crai e das demais iniciativas do Quadro 1. É um organismo da Arquidiocese de Florianópolis e Entidade-Membro da Cáritas Brasileira, criada em 17 de novembro de 1960. Suas atividades com os imigrantes começaram em 1887, quando os "Missionários de São Carlos - Scalabrinianos" prestavam auxílio para os imigrantes italianos que deixavam a Itália.

Com relação às práticas de inovação social em torno desse problema público, acompanhadas nas duas iniciativas observadas, temos que a principal incidência na esfera pública é a integração, proteção, assistência social e psicológica que ambas oferecem aos imigrantes e refugiados. 0 principal problema público advém da discriminação e falta de oportunidade de geração de trabalho e renda para esse grupo. Essas iniciativas trabalham com adultos solteiros, famílias, crianças e adolescentes. No geral, atuam na defesa de direitos, ativismo e mobilização política. A ASA também destacou que trabalha com apoio religioso e com a questão da vulnerabilidade de crianças e adolescentes. Já os principais limites de atuação referem-se ao contingente de mão de obra e à dependência dos recursos financeiros do governo.

Sobre o apoio religioso, o Pe. Sérgio narrou: "O rosto da paróquia Santa Teresinha é o rosto do imigrante". De acordo com ele, o trabalho de conscientização com os membros da comunidade (não imigrantes) vem gerando bons resultados. Essa conscientização não fica só na Paróquia Santa Teresinha. O trabalho de conscientização vem sendo realizado nas 84 paróquias da Grande Florianópolis. Quando algumas dessas paróquias são procuradas por imigrantes, todas já indicam que o imigrante procure a Paróquia Santa Teresinha (ASA). Até o fim de 2018, a iniciativa atendia 80 famílias cadastradas em Floripa.

Nas duas iniciativas, a incidência resume-se em receber, encaminhar e dar apoio aos imigrantes, sendo as principais atividades: auxílio na questão documental, oferta de trabalho, assistencialismo, língua portuguesa, trabalho com mães e crianças imigrantes e/ou refugiadas.

Observamos que, a partir da situação problemática, surge uma arena pública na qual diferentes atores, a partir de associações/parcerias, "tentam determinar suas causas, determinar seus fatores e estabelecer responsabilidades" (CEFAï, 2017a, p. 188). Por meio do processo de problematização e publicização, as cenas puderam ser argumentadas diante de vastos auditórios (CEFAï, 2017b). Surge então um embrião de uma arena pública. É nessa arena que a ação pública será discutida e, de acordo com Lascoumes e Le Galès (2012), a ação pública frequentemente dá visibilidade aos desafios públicos a fim de demonstrar seus esforços para resolvê-los. Porém o retorno da controvérsia, como é o caso do encerramento do Crai, é algo que se faz presente, demonstrando que o que parece eterno, resolvido, institucionalizado entre os pares, entra em desacordo, e a conquista de outrora é perdida, o que demanda que os atores se engajem novamente para problematizar e publicizar a sua causa, a fim de buscar soluções diante das controvérsias instauradas. 


\section{CONSIDERAÇÕES FINAIS}

A imigração humana é um processo mundial histórico e que vem se intensificando nos últimos anos. Nesse quadro, insere-se a questão dos refugiados, que também abandonam seus países por diversos motivos. Nesse cenário, as cidades tornaram-se fundamentais para que as mudanças sistêmicas radicais necessárias promovam o desenvolvimento humano mais equitativo (WOLFRAM; FRANTZESKAKI, 2016).

Diante desta realidade mundial, o problema público dos imigrantes e refugiados se faz presente em Florianópolis, e isso é refletido na emergência desses novos sujeitos, que precisam, sobretudo, de apoio e acolhimento - principais atividades realizadas pelas iniciativas apresentadas no Quadro 1. Tal necessidade acaba por sensibilizar a sociedade, que começou a se mobilizar para tentar reverter esse cenário (momento crítico). As distintas articulações, as audiências, os jogos de poder e os conflitos desdobram cenas cotidianas dentro da "arena pública" do imigrante-refugiado em Florianópolis. O Crai surgiu como uma conquista desse coletivo, e o seu fechamento é um dos principais desafios dessa arena, pois o trabalho técnico-especializado que ali se tinha não será o mesmo nos Cras, por falta de aparato profissional e até o possível entrave da língua. Uma política pública para o imigrante e refugiado soa como uma ação pública necessária. Para isso, o engajamento associativo, a organização comunitária, a sociedade civil, as entidades públicas e empresariais precisam dialogar mais e traçar uma ação pública na cidade em busca de soluções para os conflitos e tensões que se instauram.

Dessa forma, a ação pública em torno da causa do imigrante/refugiado demonstra uma parte da rede que compõe o EIS da cidade coconstruído a partir de novas práticas em torno de diferentes problemas públicos, como a questão de educação e cultura, poluição das águas e falta de saneamento básico, mobilidade, saúde, entre outros ${ }^{9}$. Assim, o estudo dos EIS a partir de arenas públicas e enquanto campos de ação coletiva exteriorizada por meio das práticas dos atores no território e de forma histórica (ANDION; ALPERSTEDT; GRAEFF, 2020) é, portanto, fértil em suas possibilidades de construção de uma forma inovada de conhecimento - traz avanços para a compreensão do fenômeno e inspiração para que novas arenas sejam investigadas. Afinal, no desenrolar do cotidiano, é preciso conceber as cidades como lugares moldados a partir da ação das comunidades e da formação de ecossistemas urbanos, com potencial de se desenvolver a inovação social. No atual cenário global, as cidades e as áreas urbanas são componentes críticos da sustentabilidade global e, ao mesmo tempo, impulsionadores da transformação social global, especialmente em termos de inovação social. Cabe então ao governo apoiar e fomentar as iniciativas nos EIS por meio de sistemas de governança, planejamento e políticas públicas adequados, com objetivo de promover a resiliência em sistemas urbanos.

Uma análise pragmatista dos fenômenos permitiu identificar e destacar as micropolíticas em arenas públicas, sua história local e a ação coletiva da sociedade. São as ações e as práticas, atuais e pretéritas, que indicam como a inovação social (enquanto mudança social) é/foi desenhada e a sua incidência nas dinâmicas de desenvolvimento dos territórios. O debate ainda precisa ser fortalecido e aprofundado em torno dos EIS, além de uma pesquisa para saber em que medida as ações empreendidas impactam a vida do imigrante/refugiado e da cidade como um todo. A relação entre a teoria e a prática mostrou como o problema público (DEWEY, 1927) vai se reconfigurando com o tempo e o surgimento de novas urgências, o que incita a mobilização

\footnotetext{
${ }^{9}$ Para mais informações, visite: http://www.observafloripa.com.br/is-page//publicProblems.
} 
dos atores. O framework do Obisf permitiu que fizéssemos diferentes análises (do macro ao micro) diante dessa causa. Por isso, ainda é necessário acompanhar mais de perto essa e outras arenas públicas, para reconhecermos como as inovações sociais emergem e contribuem para a consolidação de uma democracia participativa no território (DEWEY, 1927).

\section{REFERÊNCIAS}

ALTO COMISIONADO DE LAS NACIONES UNIDAS PARA LOS REFUGIADOS (ACNUR). Tendencias Globales: desplazamiento forzado en 2017. UNHCR/ACNUR. Disponível em: https://bit.ly/2tdyc0p. Acesso em: 2 ago. 2018.

ALTO COMISIONADO DE LAS NACIONES UNIDAS PARA LOS REFUGIADOS (ACNUR). Definição de refugiados. UNHCR/ACNUR, 2016. Disponível em: https://bit.ly/2HrcY6Q. Acesso em: 28 nov. 2017.

ANDION, C.; ALPERSTEDT, G.; GRAEFF, J. Ecossistema de inovação social, sustentabilidade e experimentação democrática: um estudo em Florianópolis. Revista de Administração Pública, v. 54, n. 1, p. 181-200, 2020.

ANDION, C.; RONCONI, L; MORAES, R.; GONSALVES, A.; SERAFIM, L. Sociedade civil e inovação social na esfera pública: uma perspectiva pragmatista. Revista de Administração Pública, São Paulo, v. 3, n. 5, p. 369-87, 2017a.

ANDION. C. ALPERSTEDT, G.; GRAEFF, J. Ecossistemas de inovação social e sua incidência nas arenas públicas da cidade: um estudo na cidade de Florianópolis, Brasil. Anais Laemos, Buenos Aires, 2017b.

ANGENENDT, S. L'Europe et le monde en 2020: essai de prospective franco-allemande. Paris: Septentrion, 2011.

ARAÚJO, A. Reve de Brezil: a inserção de um grupo de imigrantes haitianos em Santo André, São PauloBrasil. 2015. 120 p. Dissertação (Mestrado em Ciências Humanas e Sociais) - Universidade Federal do ABC (Ufabc), Santo André, SP, 2015.

BARTHE, Y. (Org.). Sociologia Pragmática: guia do usuário. Sociologias. Porto Alegre, v. 18, n. 41, p. 84129, jan./abr 2016.

BBC BRASIL. Total de mortos do Haiti chega a 230 mil e supera o do tsunami de 2004. 2010. Disponível em: https://bbc.in/2VOpqGx. Acesso em: 2 ago. 2018.

BIGNETTI, L. P. As inovações sociais: uma incursão por ideias, tendências e focos de pesquisa. Ciências Sociais Unisinos. Porto Alegre, v. 46, n. 1, p. 3-14, 2011.

BOLTANSKI, L.; THÉVENOT, L. A Sociologia da capacidade crítica. European Journal of Social Theory. Nova Delhi, v. 2, n. 3, p. 359-77, 1999.

BRASIL. Lei 13.445/2017. Lei da Migração. Brasília-DF, 2017. Disponível em: https://bit.ly/2Ebnqxf. Acesso em: 10 jan. 2018.

BRASIL. Constituição da República Federativa do Brasil. Brasília-DF, 1988. Disponível em: https://bit. Iy/2zxwfNc. Acesso em: 30 nov. 2017.

CEFAï, D. Públicos, problemas públicos e arenas públicas. O que nos ensina o pragmatismo. (Parte I). Novos Estudos CEBRAP, São Paulo, v. 36, n. 1, p. 187-213, 2017 a.

CEFAï, D. Públicos, problemas públicos e arenas públicas. O que nos ensina o pragmatismo. (Parte II) Novos Estudos CEBRAP, São Paulo, v. 36, n. 2, p. 129-42, 2017b. 
CEFAÏ, D. Grande exclusão e urgência social: cuidar dos moradores de rua de Paris. Contemporânea, Rio de Janeiro, v. 3, n. 2, p. 265-86, 2013.

DEWEY, J. The public and its problems. Chicago: Swallow Press, 1927.

FERREIRA, L. C. Após 13 anos, missão no Haiti comandada pelo Brasil se aproxima do fim. Agência Brasil, Brasília, maio 2017. Disponível em: https://bit.ly/2qBFk61. Acesso em: 2 ago. 2018.

FUNDAÇÃO GETÚLIO VARGAS. Diretoria de Análise de Políticas Públicas. Imigração e desenvolvimento. Rio de Janeiro: FGV-DAPP, 2018. Disponível em: https://bit.ly/2gaqXNH. Acesso em: 2 ago. 2018.

FONTAN, J. M. ; KLEIN, J. L ; TREMBLAY, D. G. Social innovation at the territorial level: from Path Dependency to 17 Path Building. In: DREWE, P.; KLEIN, J-L; HULSBERGEN, E. The challenge of social innovation in urban revitalization. Amsterdam: DSP, 2008.

GUSFIELD, J. The culture of public problems: drinking-driving and the symbolic order. Chicago: The University of Chicago Press, 1981.

HOWALDT, J.; SCHWARZ, M. Social innovation: concepts, research fields, and international trends. Dortmund, 2010. Disponível em: https://bit.ly/2VOh7e5. Acesso em: 10 dez. 2018.

IBGE. Florianópolis. Disponível em: https://bit.ly/2AoQONV. Acesso em: 3 mar. 2019.

JORNAL A HORA DE SC. Senegaleses protestam e pedem legalização de suas atividades como ambulantes em Floripa. 2017. Disponível em: https://bit.ly/2HqDw8d. Acesso em: 6 mar. 2019.

JORNALISTAS LIVRES (2019). Prisão abusiva de imigrante africano faz do centro de Florianópolis praça de guerra. Disponível em: https://bit.ly/2VOILaL. Acesso em: 6 mar. 2019.

JORNAL NDMAIS. Após atender 5,4 mil imigrantes, Centro de Referência fechará as portas em Santa Catarina. 2019. Disponível em: https://bit.ly/2GtW9qA. Acesso em: 20 jan. 2020.

KALETKA, C. et al. Peeling the Onion: exploration of the layers of Social Innovation Ecosystems: modelling a context sensitive perspective on driving and hindering factors for SI. European Public Social \& Social Innovation Review, v. 1, n. 2, p. 83-93, 2016.

KLEIN, J.-L. ; HARRISSON, D. L'innovation sociale. Québec: Presses de l'Université du Québec, 2007.

KLEIN, J-L. ; JETTE, C. ; CHAMPAGNE, C. ; ROY, M.; CAMUS, A. La transformation sociale par l'innovation sociale. Québec: Presses de l'Université du Québec, 2016.

LASCOUMES, P.; LE GALÈS, P. Sociologia da Ação Pública. Maceió: Edufal, 2012.

LEVESQUE, B. Économie sociale et solidaire et entrepreneur social: vers quels nouveaux écosystèmes? Reveue Interventions économiques. Quebec, n. 54, p. 1-45, 2016.

MASSEY, D. S.; KOUAOUCI, A.; PELLEGRINO, A.; ARANGO, J.; HUGO, G. Worlds in Motion: understanding international migration at the end of the millennium. Oxford: Oxford University Press, 1998.

MCPHEARSON, T.; ANDERSON, E.; ELMQVIST, T.; FRANTZESKAKI, N. Resilience of and through urban ecosystem services. [S.I.]: Ecosystem Services, 2014. Disponível em: https://bit.ly/2MAkhNg. Acesso em: 20 ago. 2019. 
MEHMOOD, A. Institutional forms of social innovation. International Journal of Innovation and Sustainable Development, Glasgow, v. 10, n. 3, p. 300-11, 2016.

MOULAERT, F. ; MARTINELLI , F.; GONZALEZ, S.; SWYNGEDOUW, E. Introduction: social innovation and governance in European cities - urban development between path dependency and radical innovation. European Urban and Regional Studies, London, v. 14, n. 3, p. 195-209, 2007.

NICHOLS, A.; SIMON, J.; GABRIEL, M.; WHELAN, C. New frontiers in social innovation research. London: Open, 2015.

OLIVEIRA, M. A. M. O imigrante e as Fronteiras: armadilhas interpretativas. In: COSTA, E.; OLIVEIRA, M. Seminários de Estudos Fronteiriços. Campo Grande, MS: Ed. UFMS, 2009.

PHILLIPS, W.; LEE, H.; GHOBADIAN, A. Social Innovation and Social Entrepreneurship: a systematic review. Group \& Organization Management, v. 40, n. 3, p. 1-10, 2014.

SAINT-DENIS, A. L'innovation sociale au service des réfugiés. Bruxelas: AEIDL, 2017. Disponível em: https:// bit.ly/31RIt3S. Acesso em: 15 ago. 2019.

SANTO, A. L. O uso de fotografias e vídeos em pesquisa qualitativa: em busca de um novo olhar sobre os territórios fronteiriços. ADM.MADE, São Paulo, v. 22, n. 2, p. 3-34, 2018.

SAYAD, A. The Suffering of the Immigrant. Cambridge: Polity Press, 2004.

SINCLAIR, S.; BAGLIONE, S. Introduction: social innovation and social policy. Social Policy and Society, v. 13, n. 3, p. 409-410, 2015.

SPAUTZ, D. Santa Catarina tem 5,7 mil imigrantes no cadastro de programas sociais. NSC Total, [S.I.], jun. 2019. Disponível em: https://bit.ly/2ZomHRh. Acesso em: 15 set. 2019.

TAYLOR, J. Introducing Social Innovation. The Journal of Applied Behavioral Science. USA, v. 6, n. 6, p. 69-77, 1970.

TEPSIE. Building the social innovation ecosystem in Europe. Portugal: The Young Foundation, 2014.

THOMÉ, L; DIOGO, M. Paraíso para os haitianos, Santa Catarina vê crescer o número de imigrantes em busca de trabalho. Portal Nd+, Florianópolis, abr. 2014. Disponível em: https://bit.ly/2Wk3ov2. Acesso em: 1ㅇago. 2019.

THOMÉ, L. Haitianos: os imigrantes do século 21 em Santa Catarina. Portal Nd+, Florianópolis, maio 2015. Disponível em: https://bit.ly/2DYgVQ8. Acesso em: 15 set. 2018.

VETRANO, N. O papel do Estado e das organizações sociais na preservação dos Direitos Humanos do trabalhador migrante. In: PRADO, E. P.; COELHO, R. (Org.) Migrações e Trabalho. Brasília: Ministério Público do Trabalho, 2015.

WOLFRAM, M.; FRANTZESKAKI, N. Cities and systemic change for sustainability: prevailing epistemologies and an emerging research agenda. Sustainability, Switzerland, v. 8, n. 144, p. 1-18, 2016. 


\section{Sobre os autores:}

Anderson Luís do Espírito Santo: Doutorando em Administração na Universidade do Estado de Santa Catarina, Centro de Ciências da Administração e Socioeconômicas (Udesc-Esag). Mestre em Estudos Fronteiriços. Graduado em Administração na Universidade Federal de Mato Grosso do Sul (UFMS). Professor do curso de Administração na UFMS, Campus do Pantanal. Pesquisador do Observatório de Inovação Social de Florianópolis. E-mail: anderson84luis@gmail.com, Orcid: http://orcid.org/0000-0001-6507-974X

Carolina Andion: Pós-doutora em Economia Social pelo Instituto Universitário de Pesquisa em Economia Social, Cooperativa e Empreendedorismo (Iudescoop) pela Universidade de Valência na Espanha. Doutora em Ciências Humanas pela Universidade Federal de Santa Catarina (UFSC). Mestre em Administração pela Escola de Hautes Études Commerciales de Montréal (HEC). Professora associada do departamento de Administração Pública do Centro de Ciências da Administração e Socioeconômicas (Esag) da Universidade Estadual de Santa Catarina (Udesc). Pesquisadora do Observatório de Inovação Social de Florianópolis. E-mail: andion.esag@gmail.com, Orcid: http://orcid.org/0000-0003-4723-3437 
